\title{
Transforming cancer outcomes in England: earlier and faster diagnoses, pathways to success, and empowering alliances
}

This article was published in the following Dove Medical Press journal: Journal of Healthcare Leadership

\author{
Christopher J Harrison' \\ Roger G Spencer ${ }^{2}$ \\ David C Shackley ${ }^{3}$ \\ 'University of Manchester Division of \\ Cancer Sciences, The Christie NHS \\ Foundation Trust, Manchester, UK; \\ ${ }^{2}$ Chief Executive's Office, The Christie \\ NHS Foundation Trust, Manchester, \\ UK; ${ }^{3}$ University of Manchester \\ Division of Cancer Sciences, Greater \\ Manchester Cancer, Manchester, UK
}

Correspondence: Christopher J Harrison University of Manchester Division of Cancer Sciences, Trust Headquarters, The Christie NHS Foundation Trust, Wilmslow Road, Manchester, M20 4BX, UK

Tel +44 I6 I446 370।

Email Christopher.harrison@christie. nhs.uk

\begin{abstract}
Cancer outcomes and patient experience in England have never been better but survival remains worse than in comparable countries. Differences in stage at diagnosis and, to a lesser extent, access to optimal treatments are likely to be the most important factors. The national cancer plan emphasizes earlier and faster diagnosis and the creation of cancer alliances providing strategic leadership and coordination. Earlier diagnosis is being promoted by national awareness campaigns designed to overcome fatalism and perceived barriers to consulting a general practitioner as well as improvements to existing screening programs and the introduction of more targeted screening such as Lung Health Checks. These are supported by local social marketing campaigns in which trained volunteers support and advise others about cancer and cancer care. The epidemiology of symptoms in general practice provides an organizing framework for cancer diagnostic pathways. Alliances are implementing a broader model of cancer diagnostic clinics at a larger scale taking into account the different needs of patients with 1) obvious alert symptoms, 2) low risk but not no risk symptoms, and 3) serious but not specific symptoms. Faster diagnosis is being promoted by the introduction of a Faster Diagnosis Standard requiring patients are given a diagnosis of cancer or have it ruled out within 28 days of referral. The three cancer alliances forming the National Cancer Vanguard together with NHS England are publishing clinically led evidence-based Timed Diagnostic Pathways which show how the drastic changes needed can be achieved. Cancer alliances have been successful in developing clinical cancer pathways which need support by improved commissioning and regulatory approaches which align clinical pathways with financial and performance ratings. Clinical leadership has been essential but further focus is needed on making sure that performance and regulatory approaches give proper attention and encouragement to earlier and faster diagnosis. Keywords: cancer, pathways, outcomes, vanguard, diagnosis, rapid
\end{abstract}

\section{The NHS landscape}

Since the first cancer plan for England was published in $2000,{ }^{1}$ there have been remarkable improvements in cancer care. More people than ever before now survive cancer and the number of people alive in the UK having had a cancer diagnosis is rapidly approaching 3 million and is projected to pass 4 million by $2030 .^{2}$ More attention is now paid to prevention and early detection of cancer, and treatments have become less toxic and more personalized. ${ }^{3}$ More patients than ever before report a positive experience of their cancer care. ${ }^{4}$ The UK has some of the world's leading cancer research groups and programs. ${ }^{5}$ Despite this, there remain unacceptable geographical differences in survival rates within England ${ }^{6}$ and reported cancer outcomes in England 
as a whole remain below those in comparable countries. ${ }^{7-9}$ Cancer Research UK (CRUK) reports that the most likely reason for this differential lower survival is the difference in stage at diagnosis. ${ }^{10}$

Reforms to the NHS introduced by the Health and Social Care Act $(2012)^{11}$ devolved greater power and budgetary control to local clinical commissioning groups (CCGs) operating with a regulated provider system. Private providers were to be able to compete with centrally accountable NHS Trusts and NHS Foundation Trusts with greater operational and financial freedoms and local accountability. ${ }^{12}$ However, the loss of regional coordination mechanisms led to widespread confusion with the loss of many of the formal cancer networks which had previously overseen cancer care and patient pathways leading to disjointed planning and variation in access to cancer care. Dissatisfaction was such that in 2014 NHS England published a Five Year Forward View ${ }^{13}$ which sought to introduce new models of care, providerprovider and provider-commissioner collaborations aimed at generating savings and efficiencies as well as improving clinical outcomes. Competition was to be replaced with strategic cooperation through system wide Sustainability and Transformation Programmes ${ }^{14}$ albeit that these were introduced without new legislation and therefore were without a statutory basis.

The Five Year Forward View identified cancer as a national clinical priority and in 2015 the government accepted the advice from an independent national cancer task force ${ }^{15}$ that much of the difference in cancer survival rates between England and comparable countries is due to later presentation to medical services. The UK has a less favorable stage distribution than comparable countries. For example, $20.3 \%$ of non-small-cell lung cancer is diagnosed at an early stage (I or II) in England compared with $25 \%$ in Canada. ${ }^{9}$

The taskforce also pointed out that onward referral to specialist care in countries with a "gatekeeping role" for primary care is later and 1 year survival lower than in those without such a filter function. General practitioners (GPs) in England see up to a quarter of cancer patients three or more times before a hospital referral and access to diagnostic tests by English GPs is less than half of that found in other countries. In addition, English GPs have poorer access to specialized advice to guide investigation or referral. ${ }^{9,15}$

The UK government also accepted the task force's 96 recommendations, thereby setting out a comprehensive 5-year plan for improving cancer care outcomes between 2015 and 2020. ${ }^{16}$ Annual national progress reports ${ }^{17,18}$ document the establishment of 19 new "cancer alliances" to lead and coordinate cancer care at a population level. The reports also detail actions across the entire plan including national efforts to prevent cancer and to ensure effective treatment services. The national plan for the cancer workforce is overseen by Health Education England. ${ }^{19}$

This review, written from the perspective of those seeking to lead local innovation and improvements in Greater Manchester and the frontline NHS in England, examines current approaches to the earlier and faster diagnosis of cancer, and ways of organizing and leading cancer care so as to speed up the translation of research-based innovations into practice. We provide examples of practical NHS initiatives to speed up cancer diagnosis and we examine the crucial leadership role of clinicians working in cancer alliances to lead cancer pathways which cross organizational boundaries.

\section{Why is earlier detection of cancer beneficial?}

Treatment when cancer is diagnosed earlier is generally

- More effective - for example, in colorectal cancer $90 \%$ of people with the earliest stage live 10 years or more compared with $5 \%$ for the most advanced disease. ${ }^{16}$

- Shorter, less complex and with less marked side effects - typically with enhanced experience of care and more positive subsequent quality of life. ${ }^{16}$

- Less expensive - for example, in colorectal cancer early stage treatment typically costs $£ 3,400$ and $£ 12,500$ for later stage. ${ }^{20}$

\section{Public awareness and consultation behavior}

Forbes et $\mathrm{al}^{21}$ studied whether people from countries with lower cancer survival (UK and Denmark) were less aware of cancer symptoms or held more negative beliefs about cancer than those from countries where survival is higher (Australia, Canada, and Sweden). UK patients were less likely to know that cancer risk increases with age and had the highest rates of perceived barriers to seeking medical advice on symptoms. This was most clearly expressed in terms of worrying about wasting the doctor's time which was cited as a cause of delay by $34 \%$ of the UK subjects compared with $21 \%, 14 \%, 12 \%$, $11 \%$, and $9 \%$ in Canada, Australia, Denmark, Norway and Sweden, respectively. ${ }^{21}$

A study by CRUK showed that although recognition of cancer alert symptoms was high, over a third of patients agreed or strongly agreed that the following things might put them off going to the doctors: "I find it difficult to get 
an appointment at a convenient time"; "I find it difficult to get an appointment with a particular doctor"; "I don't like having to talk to the GP receptionist about my symptoms"; and "I don't want to be seen as someone who makes a fuss". ${ }^{22}$

Since 2010, Be Clear on Cancer $^{23}$ (BCOC) has become a well-established program, working to improve cancer outcomes and reduce health inequalities within England. The program presents cancer messages in a credible and acceptable way for specific target population groups. Extensive clinical and public testing and piloting is undertaken in developing campaigns in order to ensure that campaigns prompt appropriate action rather than merely raising awareness of symptoms. ${ }^{24}$

BCOC Oesophago-Gastric Cancer ${ }^{25}$ campaigns in 2014 and 2015 successfully raised awareness of two important symptoms of esophago-gastric cancer (heartburn and difficulty swallowing) and prompted people to see their GP. There was a corresponding increase in the number of referrals for suspected upper gastrointestinal (upper GI) cancer and an increase in the number of cases of esophageal cancer diagnosed during the campaign period. Similar findings have been reported in other BCOC campaigns such as the national breathlessness campaign in $2017^{26}$ and the national breast cancer campaign in 2018 which targeted women over 70 years of age. ${ }^{27}$

In a prostate cancer regional pilot campaign, the key message was targeted at black men who have a one in four life-time risk of prostate cancer. Although a very small pilot localized to six London boroughs over a 4-week period, the program did show that awareness could be raised in the target group and there was a small effect on stage at diagnosis although not on any other clinical outcome indicator. ${ }^{28}$

Local cancer alliance-led initiatives can complement national campaigns. The Cancer Champion ${ }^{29}$ (Greater Manchester) and the Be Cancer Safe campaign ${ }^{30}$ (Bassetlaw and North Derbyshire) exemplify social movements in which trained members of the public spread prevention and early detection messages, support people, and prompt action throughout local communities. In Greater Manchester, the aim is to train up to 20,000 local volunteers by 2020 , and in Bassetlaw and North Derbyshire, 1,840 champions had been recruited within 2 months of the campaign launch..$^{29,30}$

Cancer treatments are increasingly effective, precise and personal, and, with some exceptions, considerably less toxic. ${ }^{3}$ Our experience is that these changes may not yet have permeated into the collective public understanding of cancer in England, and this may be one factor leading to the continued observed reticence to consult GPs because of fatalism about the condition and fear of treatment. Approaches such as BCOC in England and regional social marketing campaigns led by cancer alliances are addressing these more general underlying perceptions and barriers to consultation.

\section{Case-finding and screening of higher risk groups}

There has been much debate in England about introducing more selective screening approaches, targeted at population sub-groups at higher risk. These complement the national population-based cancer screening programs (breast, ${ }^{31}$ colorectal, ${ }^{32}$ and cervical cancer ${ }^{33}$ overseen by the National Screening Committee ${ }^{34}$ and which currently detect around 5\% of all cancer cases in England, including around 30\% of breast cancers and $10 \%$ of bowel cancers). ${ }^{35}$ With new technological approaches, there is potential to diagnose more asymptomatic cancers (and by implication, early stage) with new screening techniques. Such programs must be piloted and thoroughly evaluated before broader introduction.

Currently, there is no population screening program for lung cancer. However, the $20 \%$ mortality reduction for those screened with low-dose CT, compared with chest X-ray in the US National Lung Screening Study led to lung screening being recommended for ex-smokers aged 55-80 years in the USA and a series of small-scale pilot studies being introduced across England. ${ }^{36}$

The Manchester Lung Health Check Study was a community-based pilot of targeted, low-dose computerized tomography (LDCT) screening for lung cancer. The population covered was those who had ever smoked, aged 55-74 years, and living in some of the most economically deprived areas of Manchester. People meeting the criteria were invited to undergo a lung health check which included immediate access to LDCT for those with high risk of lung cancer. The check was undertaken in mobile facilities located next to local shopping centers. Of 1,384 patients screened, $3 \%$ had lung cancer of which $80 \%$ were at an early stage and $65 \%$ of which underwent surgical resection. ${ }^{37,38}$

The study concluded that "Taking lung cancer screening into communities, with a Lung Health Check approach, is effective and engages populations in deprived areas". Similar initiatives in Liverpool, Nottingham, and London had comparable results. ${ }^{37}$ NHS England's Clinical Expert Group for Lung Cancer has developed a service specification setting out the objectives, service requirements, and standards required for these services. A national implementation program starting with areas in England with the lowest survival rates for lung cancer is in progress. The recently released positive 
results of the Nelson trial can only support this approach and act as a prompt to consideration of a wider program. ${ }^{39}$

\section{Innovation and research in earlier diagnosis}

Innovation in the area of earlier cancer diagnosis has noticeably accelerated in recent years. Developments in the understanding of the human genome and the basic causes of cancer have enabled us to start to identify the earliest preclinical signs of cancer such as through detection in the blood of circulating tumor cells or DNA. Current advances offer huge opportunities for identifying new markers for risk, tumor development, treatment effectiveness, and relapse and over the next 5 years seem set to revolutionize how we diagnose and classify cancer.

As part of this effort, the nationally funded Biomedical Research Center ${ }^{40}$ at Manchester University has a major work program dedicated to cancer prevention and early detection. Work streams focus on risk stratification, imaging and molecular biomarkers, obesity-related cancers, and new service models such as the lung health check approach already described. The emphasis in Manchester is to "pivot" toward research of prevention and earlier detection of cancer where it is felt there is more population benefit in the long term. ${ }^{41}$

CRUK has identified the following areas of focus for research into the early detection of cancer: ${ }^{41}$

- Biological research underpinning early detection and biomarker discovery/validation

- Human-based early detection discovery research

- Population risk-stratification for early detection

- Biomedical and health informatics, and systems biology for early detection

- Development and utilization of preclinical early detection model systems

- Novel early detection technology development

- Translational/clinical early detection research

In addition, CRUK is creating an elite alliance of worldleading UK and US centers of excellence in early detection research to catalyze a step-change in progress in this field. A recent call for applications is for UK institutions to become member centers of this alliance with up to $£ 10$ million available to support two to three UK centers over 5 years. ${ }^{42}$

Earlier detection of cancer was one of the key aspects of the 2015 independent taskforce report ${ }^{16}$ and NHSE has already signaled in its consultation on the new long-term plan for the NHS that this will remain an important element of the cancer component. ${ }^{43}$

\section{Primary care assessment and referral}

Primary care assessment of possible cancer symptoms can be complex with symptoms often being similar to benign self-limiting conditions. The 2017 National Cancer Patient Experience Survey shows that just under a quarter of patents subsequently diagnosed with cancer saw their GP three times or more before referral for tests, after initially presenting in primary care. Eight percent of patients saw their GP five or more times before referral. ${ }^{4}$

In Denmark, work ${ }^{44}$ drew on the epidemiology of cancer symptoms to characterize the first symptomatic presentation of cancer patients in general practice into three groups each requiring a different type of response from the GP. About $50 \%$ of patients had "obvious" alarm symptoms requiring urgent referral, $30 \%$ had normal "common" vague symptoms requiring a specific test to exclude the possibility or confirm cancer, and $20 \%$ had symptoms that are "difficult" to assess because they are serious but not specific for cancer and that require more careful specialist assessment and investigation.

This classification is based on Danish data, but its applicability to England is consistent with the finding that $50 \%$ of cancer patients in the UK did not have symptoms that would have triggered an urgent referral under the National Institute for Health and Care Excellence guidelines recorded in their notes. ${ }^{45}$

International studies suggest that English primary care practitioners have a low propensity to refer or investigate symptoms for cancer at first presentation, have a low level of direct access to tests such as imaging for cancer, and have a low level of rapid access to specialist advice in problematic cases. Willingness to investigate at first presentation correlates with 1- and 5-year survival across a range of types of cancer. ${ }^{46}$

Countries such as England with a strong gatekeeper role for primary care have been shown to have the lowest cancer survival rates. ${ }^{47}$ This finding has underpinned policy responses in both England and Denmark which seek to support GPs rather than replace them with alternative mechanisms for cancer diagnosis.

\section{Patients with obvious alert symptoms for cancer}

The NHS in England has instituted rapid access referral pathways for specific "obvious" cancer alarm symptoms. Symptoms or groups of symptoms which indicate urgent referral to be seen within 2 weeks are defined by guidelines issued by NICE, based on the assessment of the positive predictive values (PPVs) of different symptom combinations. ${ }^{48}$ 
Updated guidance published in 2015 lowered the threshold for referral in the guidance from a PPV of about $11 \%$ to $3 \%$. As pointed out at the time of their introduction, ${ }^{49}$ this would mean that the number of referrals would dramatically increase so that rather than nine urgent referrals for one case of cancer, there would be 33 urgent referrals for one confirmed case. Indeed large increases have been recorded with the number of urgent referrals across England with suspected cancer increasing from 1.6 million in 2014/2015 to 2.0 million in $2017 / 2018 .^{50,51}$ In some pathways, the growth in referrals for urgent assessment has been very marked: in the Greater Manchester Alliance area (catchment 3 million), over the 3 years 2015-2017, there was a 40\% increase in suspected colorectal cancer referrals.

The NICE guidelines ${ }^{50}$ are clear and evidence based while leaving scope for clinical "gut feeling". They are however complex and may be difficult to recall and apply in the middle of a consultation. In addition to locally based referral forms and systems, a variety of support packages to aid GP decision-making have been introduced. For example, Gateway $\mathrm{C}^{52}$ is an online educational package originally developed by the National Cancer Vanguard (NCV) to assist GPs in understanding and applying the NG12 criteria and other aspects of cancer care. The online courses are interactive and are developed by GPs and other specialists to ensure insights from those regularly dealing with specific cancers. Originally piloted in Greater Manchester, the Gateway C approach is now available to GPs and cancer alliances across England. Gateway $\mathrm{C}$ is a training module for primary care as opposed to real-time decision support (RTDS). Increasingly, RTDS is being incorporated into primary care information technology systems which should also support primary care professionals during the consultation. ${ }^{52}$

\section{Patients with common symptoms with a "low risk" but not "no risk" of cancer}

For "common" vague symptoms that have a low risk of cancer, but the diagnosis cannot be completely excluded without investigation, the English independent task force ${ }^{16}$ recommended in 2015 that "NHS England should mandate that GPs have direct access to key investigative tests for suspected cancer - blood tests, chest $\mathrm{x}$-ray, ultrasound, MRI, CT and endoscopy - by the end of 2015". This reiterates previous initiatives going back to the 2000 Cancer Plan for England which explicitly referred to increases in diagnostic capacity and the availability of direct access to tests such as endoscopy by GPs. The NICE guidance on urgent referrals ${ }^{50}$ also contains recommendations on direct access use of tests by GPs.

A survey and an analysis of the national diagnostic imaging data $\operatorname{set}^{53}$ suggests that access to diagnostic tests has been increasing across England although not at the rate required to implement the national strategy in full. There remain variations in access and priority given to improvements in cancer diagnostic facilities between CCGs. For example, the number of imaging tests increased by 4.6 million from $2012 / 2013$ to $2015 / 2016$, and while in the same period some CCGs have seen a 6.2\% increase in CT scans, others have seen a reduction of $2.1 \% .{ }^{54}$

\section{Patients with serious but non- specific symptoms}

The $20 \%$ of cancer patients falling into the category of "difficult", ${ }^{44}$ consult GPs for the first time with non-specific or vague symptoms which while not suggestive of a specific type of cancer do indicate the probability of a serious underlying condition. These patients pose a dilemma for GPs because they do not easily fit the criteria of the NG12 pathways $^{50}$ and the clinical picture is more complex than the requirement for a single one-off test. Nevertheless, a variety of sources suggest that the likelihood of these patients having a cancer diagnosis is up to $16 \%$ with the probability of some form of serious non-cancer condition being up to a third. ${ }^{55-58}$

In England, a series of pilots of cancer pathway innovations have been undertaken through the Accelerate Coordinate Evaluate Programme (ACE). ${ }^{59,60}$ The second wave (ACE2) has concentrated on the concept of multidisciplinary cancer diagnostic clinics (MDCs) and their applicability in the NHS.

The ten ACE2 sites ${ }^{61}$ are testing pathways for patients with non-specific symptoms that could be indicative of cancer, but who do not currently meet the criteria for urgent referral. Current evidence suggests that MDCs will be an effective way to diagnose cancer within this patient group. The mid-point evaluation of the $\mathrm{ACE} 2^{62}$ reports that of patients referred to the MDCs the most common symptom was weight loss (62\%), followed by nausea and appetite loss (28\%), abdominal pain $(25 \%)$, and fatigue (20\%). GP "gut feeling" or clinical suspicion based on experience was a feature of $33 \%$ of referrals overall but with variation between the sites. Of 1,623 patients referred to the MDCs by February 2018, 142 cancers had been diagnosed (overall rate of $9 \%$; range $4 \%-15 \%$ ). ${ }^{62}$

Although the evaluation continues, NHSE has incorporated the model into its future plans and proposes to "By 
March 2018, introduce 10 new multi-disciplinary Rapid Diagnostic and Assessment Centres across England, and by March 2019, rollout centers in each of the 16 cancer alliances England NHS" ${ }^{63}$ In keeping with this approach, NHSE is working with the ACE2 and cancer alliances to produce a national timed clinical pathway with accompanying resource pack which will act as a guide to the referral criteria, investigations, pathways, and data collection requirements for the new centers.

Clarity about the primary care epidemiology ${ }^{64}$ of symptoms possibly related to cancer as they are present in patients seeking medical help can help to provide a rational basis for planning diagnostic approaches. When it comes to planning services and arranging services cost-effectively, however there is more work to do. Many of the facilities and much of the expertise needed are common across the pathways, so it might make sense to co-locate dedicated diagnostic equipment and clinical staff in one place, and if so what might be the optimum population coverage of such a service? Under this scenario how would cancer pathways requiring very specific equipment such as mammography fit? What might be the best model of clinical leadership? What size of service would be needed to have a significant impact at a whole population level?

The ACE2 pilots and the Danish experience give some insights on these issues, but there is scope to go beyond the current approaches and test out at a much larger scale what might be achievable by bringing together local provider resources into a collaborative diagnostic hub. An individual hospital may struggle to provide a rapid timely diagnostic service, not least because of workforce restraints, but it is possible that the MDC model will offer a solution by enabling standardized and rapid reporting of imaging, shared facilities, robust safety netting for test results and a "pooled" workforce.

\section{A new standard for faster diagnosis}

Efforts to make cancer diagnosis faster once patients have entered the health care system have received much attention in the NHS. These largely focus on reducing waiting after referral by setting a target for the overall time from referral to treatment of a maximum of 62 days and a number of subsidiary targets such as the 14-day maximum for referral to assessment.

There is a passionate debate in England as to the overall value of such targets and their clinical basis. For some types of cancer, faster diagnosis is crucially important. The UKLCC slogan "Millimetres Matter" reminds us that for lung cancer small delays in treatment significantly affect prognosis. For other cancer types, the impact on survival of achieving faster diagnosis may be less. Cancer waiting time measures are, however, perceived as a barometer of the effectiveness of the local cancer system both from a political standpoint and also by the public and media.

The national cancer task force ${ }^{16}$ recommended introduction of a new standard for faster diagnosis under which patients would be told whether they have cancer or not within 28 days of referral. When fully implemented in 2020 this Faster Diagnosis Standard (FDS) will replace the current 14-day maximum waiting time from referral to assessment. It is argued that the wait from referral to diagnosis (or confirmation that they do not have cancer) is more meaningful for patients.

NHSE has undertaken five pilots of the FDS to develop and test methods for measuring achievement of the standard, the definitions to be used, the additional capacity requirements for different cancer types, and the overall feasibility of introducing this measure. The pilot sites covered gynecology, urology, head and neck, lung, lower and upper GI cancer pathways. Based on the evidence from the pilot sites and in preparation for the new standard, an updated national Cancer Waiting Times information system was introduced from April 2018. Data collection for all patients will be in place in 2019 with the system being used to monitor FDS from April 2020. ${ }^{65}$

\section{Timed diagnostic pathways (TDPs)}

The FDS pilot programs confirmed that the new standard will require radical rethinking of how cancer pathways work in many parts of England. To enable this, clinical leaders across the three parts of the NCV (Greater Manchester Cancer, Royal Marsden Partners, and the University College London Hospitals Cancer Collaborative) came together with NHSE's Clinical Expert Groups to develop a series of TDPs. ${ }^{66}$ These show how timely and effective cancer diagnosis and care can be provided within the specified timescales. The pathways have also been shaped and endorsed by NHS England's Clinical Steering Group and complement existing resources such as NICE Guidelines (including NG12) and crucially have involved patients at all stages.

The first three published TDPs cover colorectal, ${ }^{67}$ lung, ${ }^{68}$ and prostate ${ }^{69}$ cancers, and their implementation has been made mandatory for CCGs by NHSE. ${ }^{70} \mathrm{~A}$ further pathway for esophago-gastric cancer is in preparation. Each pathway and supporting handbook sets out how diagnosis within 28 days can be achieved by innovative approaches to the sequencing of tests, senior clinical oversight of the system, and limiting 
the need for more invasive tests to those who will benefit most. Typically the pathways encourage streamlined, more rapid diagnostics and a treatment-focused multidisciplinary team meeting by day 21 after GP referral.

The resources published alongside each handbook support cancer alliances with implementation, and with the large-scale transformation across required whole systems. TDPs provide standardized pathways which are easier to benchmark, audit, and improve. They provide evidence-based guidance with which to help deliver the FDS and 62-day standard, improve patient experience, reduce unnecessary appointments and tests, and lead to a reduction in the marked unwarranted variation in cancer care across the country.

The clinical leaders involved in developing the pathways have identified a generic good practice checklist for managing cancer pathways within the NHS: ${ }^{69-71}$

- Daily senior triage of referrals to ensure appropriate investigations

- Straight to test and one-stop clinics to reduce unnecessary clinic attendances

- Reporting of scans immediately or within 24 hours

- Diagnostic "bundles" to reduce time taken by sequential testing

- Pathway navigators to ensure good communication and coordination

- Clear agreed protocols to avoid unnecessary consultations

- Avoid repeated MDTs to avoid delays and indecision

Examples of the innovations introduced by the nationally mandated TDPs include:

- Replacement of the traditional outpatient model for colorectal cancer with a straight to test approach based on a triage system undertaken by either a senior nurse or a doctor. ${ }^{69}$

- Consistent introduction of multi-parametric Magnetic Resonance Imaging early in prostate cancer diagnosis, thereby reducing prostate biopsies by up to $27 \%{ }^{71}$

- Reinforcing the concept of "straight to CT" for patients with abnormal chest X-rays in lung cancer diagnosis, thereby speeding up access to potentially curative treatment..$^{70}$

These clinically led national initiatives are leading to improvements in patients as they are introduced locally by cancer alliances with the impact being seen in national data. Early unpublished evidence following the introduction of the TDPs shows rapid improvements with for example achievement of the 62-day treatment standard improving from $44 \%$ to $78 \%$ for prostate cancer, $58 \%$ to $84 \%$ for colorectal cancer, and $62 \%$ to $75 \%$ for lung cancer. ${ }^{7}$

Our experience of producing the TDPs shows that with the right clinical leadership and commitment, sufficient clinical consensus to take action can be achieved in a short time frame. This work has been positively received with the high level of clinical buy in enabling the incorporation of the pathways into national commissioning guidance. ${ }^{72}$ Future work will expand the scope of the pathways to include primary care elements, treatment pathways, and ongoing care.

\section{Cancer alliances, the cancer vanguard, and the role of clinicians}

In line with the National Cancer Taskforce recommendations, 19 cancer alliances were created across England from 2016 to provide coordination and leadership of cancer care for populations of up to 6.3 million. They were tasked by NHS England $^{72}$ with:

- Ensuring collaborative working across their locality

- Aligning with Sustainability and Transformation Partnerships (STPs)

- Focusing on place-based approaches to improve cancer outcomes

- Implementing the recommendations of the National Cancer Taskforce

- Using additional transformation funding to achieve earlier and faster cancer diagnosis

- Rolling out personalized care and support for people during and after their cancer treatment

Three of the alliances (Greater Manchester, North Central and North East London, and North West and South West London collectively covering 10.7 million people or $18 \%$ of England's population) were initially designated together (between 2015 and 2018) as the NCV with the additional task of developing new models of care and tools for measuring cancer outcomes that could be applied consistently across the country. ${ }^{73}$ A key feature of alliances was the inclusion of people affected by cancer in their governance and work programs, along with the extensive stakeholder involvement. These wider perspectives gave more legitimacy and energy to the projects undertaken.

Cancer alliances operate in a complex NHS environment with a mixture of statutory bodies such as NHS Trusts, NHS Foundation Trusts, and CCGs with non-statutory arrangements such as Sustainability and Transformation Plans and a variety of new models of inter-provider cooperation such as the "group" model exemplified by The Northern Care 
Alliance NHS Group, ${ }^{74}$ which brings together two large NHS providers (Salford Royal Hospitals and Pennine Acute Hospitals) or the service "chain" model exemplified by Moorfields Eye Hospital NHS Foundation Trust ${ }^{75}$ and The Christie NHS Foundation Trust ${ }^{76}$ which provide extensive networks of specialist services. The NHS landscape is also characterized by moves to integrate health and social care and devolve health and social care budgets and accountability to more local level (eg, Greater Manchester Health and Social Care Partnership), ${ }^{77}$ moves to bring together and achieve consistency between national regulators, ${ }^{78}$ and funding increases below levels required to keep pace with demographic trends. ${ }^{79}$

Securing improvements in cancer care in this environment is challenging and requires strong clinical networks and leadership coupled with organizational buy-in to achieve change. A notable feature of the cancer vanguard and other leading cancer alliances is the strong clinical focus and leadership. The three alliances of the NCV each had a preexisting system of clinical pathway boards to provide leadership and expertise for each type of cancer. The websites of Greater Manchester Cancer, ${ }^{80}$ Royal Marsden Partners, ${ }^{81}$ and UCLH Cancer Collaborative ${ }^{82}$ set out the detailed arrangements but what they have in common is clearly appointed clinical leadership, wide multidisciplinary membership, a focus on cross-organizational pathways of care, and a reporting mechanism to an overall board via a senior and credible medical leader responsible for the overall leadership of the alliance.

Cancer alliances across England have senior clinical leaders, and increasing alliances are establishing leadership for clinical cancer pathways which cross the boundaries of individual institutions building on the recent lessons of the cancer vanguard. Also available are NHSE's Clinical Expert Groups (CEGs) which bring together national experts to provide tumor-specific clinical expertise.

The vanguard alliances together with the CEGs led the way in developing the TDPs with supporting material to assist implementation by cancer alliances. Further supported by a national cancer dashboard ${ }^{83}$ which provides information on the progress by individual trust and local commissioning group, this approach is designed to provide a clinically led system in which variations are systematically identified and tackled. The vanguard alliances also pioneered a new relationship with industry through the "Pharma Challenge" in which commercial partners were challenged to propose clinical projects which would support implementation of vanguard plans ${ }^{84}$ and tested out other clinically important initiatives such as Gateway C..$^{54}$
Cancer alliances are seen by NHSE as providing “cancerspecific leadership for the new Sustainability and Transformation Plan (STP) footprints" ${ }^{85}$ The King's Fund ${ }^{86}$ has described STPs as a "conscious workaround" of the fragmented health system created by the Health and Social Care Act 2012. The Health Service Governance Handbook ${ }^{87}$ suggests they are grappling with such basic governance questions such as accountability, patient and public engagement, relationships with local government, balancing rapid with transparent decision-making, clinical engagement, the role of lay members and non-executives, and audit and assurance processes. It is not surprising that these issues also remain a challenge for cancer alliances despite the guidance from NHSE. ${ }^{8}$

Cancer alliances and similar models also pose challenges for regulators in working out how to place service contracts, work with partnerships rather than individual organizations, allocate funding, share risk and rewards, and measure and rate performance. ${ }^{89}$ One objective of the cancer vanguard was to explore these issues but while much progress has been made in improving cancer commissioning as recommended by the independent cancer task force ${ }^{16}$ particularly through the establishment of alliances, the specific recommendation that "the entire cancer pathway in at least one area should have a fully devolved budget over multiple years, based on achieving a pre-specified set of outcomes" has been proven problematic. The reasons for this are being evaluated, but lessons learned will be useful in future attempts to align the success of cancer alliance clinical pathway boards in designing new streamlined pathways of care with financial and commissioning incentives. Cancer commissioning systems in England remain fragmented and variably effective, and this must be addressed if, for example, the increase in deaths from breast cancer projected in an analysis by Breast Cancer Now is to be averted. ${ }^{89}$

At system level, the link between research, innovation, education, and high-quality care and outcomes is enshrined in the construct of the comprehensive cancer center (CCC) or system which finds slightly different manifestations in the $\mathrm{USA}^{90}$ and Europe. ${ }^{91}$ Within the CCC, the concept of "team science" in which scientists and clinicians work together to create clinically meaningful questions and produce implementable solutions can flourish. The challenge is then to spread the innovation beyond the immediate reach of the CCC to ensure consistent and equitable nationwide implementation.

Our experience is that the combination of a CCC providing a distributed service network with a strong cancer alliance securely tied into the overall health governance system of a 
region is a powerful driver for on the ground implementation of the national cancer plan, rapid adoption of innovation, and equitable access to care across a large population.

Our proposition is that the leadership of cancer alliances in England could beneficially be accompanied by stronger and more consistent networking of the operational service delivery system. This should be reinforced by refocusing of the commissioning and regulatory regimes, so that they actively support clinical pathways and ensure focus on the prevention, early detection and faster diagnosis of cancer that will enable the new treatments at our disposal to have the greatest possible effect.

\section{Conclusion}

National and local initiatives described in this review are addressing the apparent stoicism and behavioral reserve that may be delaying English patients consulting GPs and are building clearer evidence-based pathways and capacity to enable GPs to refer or investigate appropriately at an earlier stage. Nationally mandated diagnostic pathways are being implemented which are having early success in driving the changes needed to diagnose or rule out cancer within 28 days of referral. The application of the concept of the MDC in England is being actively explored with some alliances prepared to take a bolder approach and test the concept at a much larger scale than has until now been attempted.

Clinically led initiatives and a strong patient voice coordinated by cancer alliances have been shown to be capable of reforming care for patients and are a cause for optimism. As cancer alliances mature, we anticipate that they will benefit from further innovative approaches to provider collaboration with networks based on the CCC model being our preferred approach to ensuring dissemination of good practice. At the same time, ensuring greater alignment of regulators and less fragmentation of commissioners to enable them to concentrate on what really matters should be a national priority.

\section{Disclosure}

The authors report no conflicts of interest in this work.

\section{References}

1. Department of Health. The NHS cancer plan: a plan for investment, a plan for reform. 2000. The National Archives Website. Available from: https://webarchive.nationalarchives.gov.uk/20120503231511/ http://www.dh.gov.uk/en/Publicationsandstatistics/Publications/ PublicationsPolicyAndGuidance/DH_4009609?PageOperation=email Accessed November 5, 2018.

2. Maddams J, Utley M, Møller H. Projections of cancer prevalence in the United Kingdom, 2010-2040. Br J Cancer. 2012;107(7):1195-1202.

3. Our Year in Review - 2017/18. CRUK website. Available from: https:// www.cancerresearchuk.org/our-year-2017-18. Accessed August 28, 2018
4. Quality Health. National Cancer Patient Experience Survey. NCEPES website. Available from: www.ncpes.co.uk. Accessed September 29, 2018.

5. National Cancer Research Institute. Accelerating cancer research - a strategy for collaboration between cancer research funders in the UK (2017-22). NCRI website. Available from: http://www.ncri.org.uk/ wp-content/uploads/2017/04/NCRI-Strategy-2017-2022.pdf. Accessed August 1, 2018.

6. Atlas of Variation in Healthcare 2015. NHSE website. Available from: http://tools.england.nhs.uk/images/atlas15/atlas.html. Accessed September 1, 2018.

7. Allemani C, Matsuda T, di Carlo V, et al. Global surveillance of trends in cancer survival 2000-14 (CONCORD-3): analysis of individual records for 37513025 patients diagnosed with one of 18 cancers from 322 population-based registries in 71 countries. Lancet. 2018;391(10125):1023-1075.

8. Coleman MP, Quaresma M, Berrino F, et al. Cancer survival in five continents: a worldwide population-based study (CONCORD). Lancet Oncol. 2008;9(8):730-756.

9. International Cancer Benchmarking Partnership: Overview 2018. CRUK website; 2018. Available from: https://www.cancerresearchuk.org/sites/ default/files/icbp_findings_current.pdf. Accessed September 14, 2018.

10. Cancer in the UK 2018. CRUK website; 2018. Available from: www. cancerresearchuk.org/sites/default/files/state_of_the_nation_apr_2018_ v2_0.pdf. Accessed September 3, 2018.

11. Health and Social Care Act 2012. Gov.uk website. Available from: http:// www.legislation.gov.uk/ukpga/2012/7/contents/enacted. Accessed July $5,2018$.

12. Timmins N. The world's biggest quango' - the first five years of NHS England. The Kings Fund, and The Institute for Government. The King 's Fund website. 2018. Available from: https://www.kingsfund.org.uk/ sites/default/files/2018-05/worlds_biggest_quango_ifg_may2017.pdf. Accessed August 2, 2018

13. NHS England. Five year forward view. NHSE website. Available from: https://www.england.nhs.uk/wp-content/uploads/2014/10/5yfv-web.pdf October 2014. Accessed July 5, 2018.

14. The King's Fund. Sustainability and transformation plans (STPs) explained. King's Fund website. Available from: https://www.kingsfund. org.uk/topics/integrated-care/sustainability-transformation-plansexplained. Accessed September 3, 2018.

15. Cancer Strategy in England. CRUK website. Available from: https:// www.cancerresearchuk.org/about-us/cancer-strategy-in-england. Accessed September 3, 2018.

16. Independent Cancer Taskforce. Achieving world-class cancer outcomes a strategy for England 2015-2020. 2015. CRUK Website. Available from: https://www.cancerresearchuk.org/sites/default/files/achieving_ world-class_cancer_outcomes_-_a_strategy_for_england_2015-2020. pdf. Accessed October 1, 2018.

17. National Cancer Transformation Programme. Achieving world-class cancer outcomes: a strategy for England 2015-2020 - Progress report 2016-17, NHSE website, 2017; 2017. Available from: https://www.england.nhs.uk/cancer/strategy/achieving-world-class-cancer-outcomesprogress-report-2016-2020/. Accessed July 6, 2018.

18. Transformation Programme. Achieving world-class cancer outcomes: progress report 2016-2020. NHSE Website. Available from: https://www. england.nhs.uk/cancer/strategy/achieving-world-class-cancer-outcomesprogress-report-2016-2020 Accessed November 12018.

19. Health Education England. Cancer Workforce Plan - Phase 1: delivering the cancer strategy to 2021. 2017. HEE website. Available from: www.hee. nhs.uk/our-work/cancer-workforce-plan. Accessed September 11, 2018.

20. Incisive Health. Saving lives, averting Costs. CRUK website. Available from: https://www.cancerresearchuk.org/sites/default/files/saving_lives_averting_costs.pdf. Accessed June 5, 2018.

21. Forbes LJ, Simon AE, Warburton F, et al. Differences in cancer awareness and beliefs between Australia, Canada, Denmark, Norway, Sweden and the UK (the International Cancer Benchmarking Partnership): do they contribute to differences in cancer survival? Br J Cancer. 2013;108(2):292-300. 
22. Power E, Connor K, Crawford C. Cancer awareness measure. CRUK website; 2017. Available from: https://www.cancerresearchuk.org/sites/ default/files/cam_2017_key_findings_201808.pdf. Accessed June 5 2018.

23. Be Clear on Cancer. NHS England website. Available from: https:// www.nhs.uk/be-clear-on-cancer. Accessed August 10, 2018.

24. Be Clear on Cancer - resources. PHE website. Available from: https:// campaignresources.phe.gov.uk/resources/campaigns/16-be-clear-oncancer. Accessed September 4, 2018.

25. National Cancer Registration and Analysis Service. Oesophago-gastric cancer awareness campaign - evaluation results. PHE website. Available at http:// www.ncin.org.uk/cancer_type_and_topic_specific_work/topic_specific_ work/be_clear_on_cancer/oesophagogastriccancerevaluationresults. Accessed January 9, 2018.

26. Be Clear on Cancer-Respiratory Campaign 2017. PHE website. Available from: https://campaignresources.phe.gov.uk/resources/campaigns/46respiratory-symptom-awareness/resources. Accessed September 4, 2018.

27. Be Clear on Cancer - Breast Cancer Campaign 2018. PHE website. Available from: https://campaignresources.phe.gov.uk/resources/campaigns/31/resources/3692. Accessed September 4, 2018.

28. National Cancer Registration and Analysis Service. Prostate cancer awareness campaign - evaluation results. PHE website. Available at http://www.ncin.org.uk/cancer_type_and_topic_specific_work/topic_ specific_work/be_clear_on_cancer/prostatecancerevaluationresults Accessed January 9, 2018.

29. Greater Manchester Cancer. Achieving World-class Cancer Outcomes: Taking charge in Greater Manchester 2017-2021. Greater Manchester Combined Authority website. Available from: http://tameside. moderngov.co.uk/documents/s15734/ITEM\%206\%20-\%20GM\%20 Cancer\%20Plan.pdf. Accessed September 4, 2018.

30. Be Cancer Safe - North Derbyshire. Be Cancer Safe website. Available from: https://www.becancersafe-nd.org. Accessed September 4, 2018.

31. Breast Screening Overview. Gov.uk website. Available from: https:// www.gov.uk/guidance/breast-screening-programme-overview. Accessed August 27, 2018.

32. Bowel Screening Overview. Gov.uk website. Available from: https:// www.gov.uk/guidance/bowel-cancer-screening-programme-overview. Accessed August 27, 2018.

33. Cervical Screening Overview. Gov.uk website. Available from: https:// www.gov.uk/guidance/cervical-screening-programme-overview. Accessed August 27, 2018.

34. UK National Screening Committee. Gov.uk website. Available from: https://www.gov.uk/government/groups/uk-national-screening-committee-uk-nsc. Accessed August 27, 2018.

35. Elliss-Brookes L, McPhail S, Ives A, et al. Routes to diagnosis for cancer - determining the patient journey using multiple routine data sets. Br J Cancer. 2012;107(8):1220-1226.

36. ACE Programme. Proactive approaches to individuals at high risk of lung cancer. CRUK website. Available from: https://www.cancerresearchuk.org/sites/default/files/ace_proactive_lung_report_with_economic_evaluation_final_version_1.1a.pdf. Accessed September 3, 2018.

37. MacMillan Cancer Improvement Partnership. Manchester's Lung Health Check Pilot, August 2016. Available from: https://www.macmillan.org. uk/_images/lung-health-check-manchester-report_tcm9-309848.pdf. Accessed March 4, 2018.

38. Crosbie PA, Balata H, Evison M, et al. Implementing lung cancer screening: baseline results from a community-based 'Lung Health Check' pilot in deprived areas of Manchester. Thorax. Published Online First: 13 February 2018.

39. Press Release: NELSON Study Shows CT Screening for Nodule Volume Management Reduces Lung Cancer Mortality by 26 Percent in Men. IASLC 19th World Conference on Lung Cancer, 23-26th September 2018. Available from: https://wclc2018.iaslc.org/media/2018\%20 WCLC\%20Press\%20Program\%20Press\%20Release\%20De\%20 Koning\%209.25\%20FINAL\%20.pdf. Accessed September 30, 2018.

40. Manchester Biomedical Research Centre. NIHR website. Available from: https://www.manchesterbrc.nihr.ac.uk. Accessed July 22, 2018.
41. New Funding for Early Detection Research. CRUK website. Available from: https://www.cancerresearchuk.org/funding-forreseachers/research-features/2017-06-19-new-funding-for-earlydetection-research. Accessed September 15, 2018.

42. International Cancer Early Detection (ICED) Alliance. CRUK website. Available from: https://www.cancerresearchuk.org/fundingfor-researchers/our-funding-schemes/international-cancer-earlydetection-iced-alliance. Accessed September 10, 2018.

43. Developing the Long Term Plan for the NHS. NHS England website. Available from https://www.engage.england.nhs.uk/consultation/ developing-the-long-term-plan-for-the-nhs/user_uploads/developingthe-long-term-plan-for-the-nhs-v2.pdf. Accessed September 15, 2018.

44. Vedsted P, Olesen F. A differentiated approach to referrals from general practice to support early cancer diagnosis - the Danish three-legged strategy. Br J Cancer. 2015;112(S1):S65-S69.

45. Neal RD, Din NU, Hamilton W, et al. Comparison of cancer diagnostic intervals before and after implementation of NICE guidelines: analysis of data from the UK General Practice Research Database. Br J Cancer. 2014;110(3):584-592.

46. Rose PW, Rubin G, Perera-Salazar R, et al. Explaining variation in cancer survival between 11 jurisdictions in the International Cancer Benchmarking Partnership: a primary care vignette survey. BMJ Open. 2015;5(5):e007212.

47. Vedsted P, Olesen F. Are the serious problems in cancer survival partly rooted in gatekeeper principles? An ecologic study. Br J Gen Pract. 2011;61(589):e508-e512.

48. NICE. Suspected Cancer: Recognition and Referral - NICE Guideline [NG12]. NICE website. Available from: https://www.nice.org.uk/guidance/ng12 Updated July 2017. Accessed September 25, 2018.

49. Barraclough K. New NICE guidance on referral for cancer. BMJ. 2015;351:h3640.

50. Pearson J, Kaitesi Y, Doherty K, et al. Waiting Times for Suspected and Diagnosed Cancer Patients: 2014-15 Annual Report, NHSE website; May 2015. Available from: https://www.england.nhs.uk/statistics/ wp-content/uploads/sites/2/2015/05/CancerWaitingTimesAnnualReport_201415_Final.pdf. Accessed September 10, 2018.

51. Hamilton M, Hodgson O, Dai Det al. Waiting Times for Suspected and Diagnosed Cancer Patients - 2017-18 Annual Report, NHSE website; 2018. Available from: https://www.england.nhs.uk/statistics/ wp-content/uploads/sites/2/2018/06/Cancer-Waiting-Times-AnnualReport-201718.pdf June. Accessed September 10, 2018.

52. On-line Education for Primary Care. Gateway C website. Available from: https://www.gatewayc.org.uk/. Accessed September 26, 2018.

53. Capacity to diagnose? An analysis of cancer diagnostic activity in England, CRUK website; March 2018. Available from: https://www. cancerresearchuk.org/sites/default/files/mar18_capacity_to_diagnose. pdf. Accessed June 5, 2018.

54. Diagnostic Imaging Dataset. HSCIC website. Available from: https:// did.hscic.gov.uk. Accessed September 20, 2018.

55. Ingeman ML, Christensen MB, Bro F, Knudsen ST, Vedsted P. The Danish cancer pathway for patients with serious non-specific symptoms and signs of cancer - a cross-sectional study of patient characteristics and cancer probability. BMC Cancer. 2015;15(1):421.

56. Moseholm E, Lindhardt BØ. Patient characteristics and cancer prevalence in the Danish cancer patient pathway for patients with serious non-specific symptoms and signs of cancer - a nationwide, populationbased cohort study. Cancer Epidemiol. 2017;50(Pt A):166-172.

57. Næser E, Fredberg U, Møller H, Vedsted P. Clinical characteristics and risk of serious disease in patients referred to a diagnostic centre: a cohort study. Cancer Epidemiol. 2017;50(Pt A):158-165.

58. Forster AS, Renzi C, Lyratzopoulos G. Diagnosing cancer in patients with 'non-alarm' symptoms: learning from diagnostic care innovations in Denmark. Cancer Epidemiol. 2018;54:101-103.

59. Fuller E, Fitzgerald K, Hiom S. Accelerate, coordinate, evaluate programme: a new approach to cancer diagnosis. $\mathrm{Br} \mathrm{J}$ Gen Pract. 2016;66(645):176-177. 
60. The ACE Programme: Improving the early diagnosis of cancer. A report from the wave 1 projects. CRUK website; September 2017. Available from: https://www.cancerresearchuk.org/sites/default/files/ace_overview_report_v1.0_080917.pdf. Accessed September 15, 2018.

61. THE ACE Programme. Multidisciplinary Diagnostic Centre (MDC) based pathways for patients with non-specific but concerning symptoms - interim report. CRUK website; May 2018. Available from: https:// www.cancerresearchuk.org/sites/default/files/ace_programme_mdc_ interim_report_may_2018v2.4.pdf. Accessed September 18, 2018.

62. The ACE Programme. Emerging MDC models and principles. CRUK website. 2018. Available from: https://www.cancerresearchuk.org/sites/ default/files/emerging_mdc_models_and_principles_ace_wave_2_-jan_18_projects.pdf. Accessed September 18, 2018.

63. NHSE. Next steps on the NHS Five Year Forward View. NHSE website; March 2017. Available from: https://www.england.nhs.uk/wp-content/ uploads/2017/03/NEXT-STEPS-ON-THE-NHS-FIVE-YEAR-FORWARD-VIEW.pdf. Accessed June 5, 2018.

64. Hannaford PC, Smith BH, Elliott AM. Primary care epidemiology: its scope and purpose. Fam Pract. 2006;23(1):1-7.

65. Diagnosing Cancer Earlier and Faster. NHSE website. Available from: https://www.england.nhs.uk/cancer/early-diagnosis. Accessed June 18, 2018.

66. Rapid Cancer Assessment and Diagnostic Pathways. NHSE website. Available from: https://www.england.nhs.uk/publication/rapid-cancerdiagnostic-and-assessment-pathways. Accessed September 15, 2018.

67. Harrison C, Machesney M, Shackley D, for NHSE. Implementing a timed colorectal cancer diagnostic pathway. NHSE website; April 2018. Available from: https://www.england.nhs.uk/wp-content/ uploads/2018/04/implementing-timed-colorectal-cancer-diagnosticpathway.pdf. Accessed May 2018.

68. Harrison C, Baldwin D, Shackley D, for NHSE. Implementing a timed lung cancer diagnostic pathway. NHSE website; April 2018. Available from: https://www.england.nhs.uk/wp-content/uploads/2018/04/implementingtimed-lung-cancer-diagnostic-pathway.pdf. Accessed May 2018.

69. Harrison C, Ahmed H, Shackley D, for NHSE. Implementing a timed prostate cancer diagnostic pathway, NHSE website; April 2018. Available from: https://www.england.nhs.uk/wp-content/uploads/2018/04/implementingtimed-prostate-cancer-diagnostic-pathway.pdf. Accessed May 2018.

70. NHS England and NHS Improvement. Refreshing NHS Plans for 2018/19. NHSE website . Available from: https://www.england.nhs.uk/ wp-content/uploads/2018/02/planning-guidance-18-19.pdf. Accessed September 292018.

71. Stacey C, Shackley D, Evison M. et al. Implementing new models and standards for earlier and faster diagnosis of cancer. Lecture presented at NHS Health and Care Innovation Expo, Manchester, UK 2018. Available from: https://www.england.nhs.uk/expo/wp-content/uploads/ sites/18/2018/09/13.45-Transforming-cancer-care.pdf. Accessed September 20, 2018.

72. National Cancer Transformation Programme. Delivering world-class cancer outcomes: guidance for cancer alliances and the national cancer vanguard. NHSE website. Available from: https://www.england.nhs.uk/ cancer/strategy/alliance-guidance/ 6 December 2016. Accessed August 10, 2018.

73. The Cancer Vanguard. Cancer Vanguard website. Available from: www. cancervanguard.nhs.uk/national-cancer-strategy/. Accessed September $11,2018$.
74. Northern Care Alliance Group. PAT website. Available from: http:// www.pat.nhs.uk/about-us/northern-care-alliance.htm. Accessed September $15,2018$.

75. Moorfields NHSFT website. Available from: https://www.moorfields. nhs.uk/content/our-locations-0. Accessed September 15, 2018.

76. The Christie NHSFT website. Available from: https://www.christie.nhs. uk/. Accessed September 15, 2018.

77. Greater Manchester Combined Authority website. Available from: http:// www.gmhsc.org.uk. Accessed September 15, 2018.

78. NHS Improvement. Single Oversight Framework for NHS Providers. NHSI website. Available from: https://improvement.nhs.uk/resources/ single-oversight-framework/ 13 September 2016, Updated 10 July 2018. Accessed September 15, 2018.

79. The Kings Fund. The NHS budget and how it has changed. The King's Fund website; July 2, 2018. Available from: https://www.kingsfund. org.uk/projects/nhs-in-a-nutshell/nhs-budget. Accessed September 15, 2018.

80. Greater Manchester Cancer. Clinical Pathway Boards. GMC website. Available from: https://gmcancer.org.uk/our-areas-of-work/pathwayboards/. Accessed September 16, 2018.

81. RM Partners. Accountable Clinical Network. RM partners website. Available from: http://rmpartners.cancervanguard.nhs.uk/. Accessed September 16, 2018

82. UCLH Cancer Collaborative. UCLH website Available from: https:// www.uclh.nhs.uk/OurServices/ServiceA-Z/Cancer/NCV/Pages/NationalCancerVanguard.aspx. Accessed September 16, 2018.

83. National Cancer Dashboard. PHE website. Available from: https://www. cancerdata.nhs.uk. Accessed June 10, 2018

84. Pharmacy Challenge. Cancer Vanguard website. Available from: https:// cancervanguard.nhs.uk/pharma-challenge/. Accessed September 16, 2018.

85. The National Cancer Transformation Team. Achieving world-class cancer outcomes: Taking the strategy forward (Gateway 05215). NHSE website. Available from: https://www.england.nhs.uk/wp-content/ uploads/2016/05/cancer-strategy.pdf. Accessed September 16, 2018.

86. The King's Fund. Delivering sustainability and transformation plans The King's Fund website; February 21, 2017. Available from: https:// www.kingsfund.org.uk/publications/delivering-sustainability-andtransformation-plans. Accessed September 12, 2018.

87. Lea C. The ICSA Health Service Governance Handbook. 2nd edn London, UK: ICSA; 2017.

88. National Cancer Transformation Team. Delivering world-class cancer outcomes: guidance for cancer alliances and the national cancer vanguard (gateway reference) 05922, NHSE website. Available from: https://www.england.nhs.uk/wp-content/uploads/2017/02/canceralliance-guidance.pdf. Accessed June 15, 2018.

89. Breast Cancer Now. UK breast cancer deaths 'set to rise by 2022', new analysis shows. Breast Cancer Now website. Available from: https:// breastcancernow.org/news-and-blogs/news/uk-breast-cancer-deathsset-to-rise-by-2022-new-analysis-shows. Accessed September 29, 2018

90. Office of Cancer Centers. National Cancer Institute website. Available from: https://cancercenters.cancer.gov. Accessed September 27, 2018.

91. Saghatchian M, Thonon F, Boomsma F, et al. Pioneering quality assessment in European cancer centers: a data analysis of the organization for European cancer institutes accreditation and designation program. J Oncol Pract. 2014;10(5):e342-e349.
Journal of Healthcare Leadership

\section{Publish your work in this journal}

The Journal of Healthcare Leadership is an international, peer-reviewed, open access journal focusing on leadership for the health profession. The journal is committed to the rapid publication of research focusing on but not limited to: Healthcare policy and law; Theoretical and practical aspects of healthcare delivery; Interactions between healthcare and society and evidence-based practices;
Interdisciplinary decision-making; Philosophical and ethical issues; Hazard management; Research and opinion for health leadership; Leadership assessment. The manuscript management system is completely online and includes a very quick and fair peer-review system. Visit http://www.dovepress.com/ testimonials.php to read real quotes from published authors. 